\title{
Nocturnal blood pressure profile in obstructive sleep apnea syndrome patients without hypertension
}

\author{
Shereen Farghaly ${ }^{1}$, Lamees M. Bakkar ${ }^{1}$
}

\begin{abstract}
INTRODUCTION Obstructive sleep apnea syndrome (OSAS), which can affect nocturnal blood pressure patterns even in non-hypertensive people, has been known to increase cardiovascular and cerebrovascular risk. The aim of the study is to evaluate nocturnal blood pressure patterns and fluctuations in OSAS patients without hypertension (HTN) and to determine polysomnographic parameters associated with nocturnal blood pressure fluctuations.

METHODS This retrospective study included 100 OSAS patients without hypertension diagnosed by polysomnography. Those with $\mathrm{AHI} \geq 30$ were considered severe cases of OSAS. Sleep stages (REM, NREM), respiratory parameters (AHI, T90, ODI, average oxygen level) and blood pressure parameters during sleep (average systolic and diastolic BP, nocturnal blood pressure fluctuation index NBPFI) were recorded.

RESULTS Average systolic BP, diastolic BP and NBPF index were significantly higher in severe OSAS patients compared to non-severe patients and during REM compared to NREM stage. After adjustment of age and BMI, AHI was the only dependent factor associated with nocturnal BP fluctuation during sleep.

CONCLUSIONS Nocturnal blood pressure elevation and fluctuations are common in OSAS patients without HTN. AHI is the only dependent predictor associated with nocturnal blood pressure fluctuations in OSAS patients. Thus, it was suggested that OSAS patients are at risk to both cardiovascular and cerebrovascular problems related to nocturnal BP fluctuations during sleep.
\end{abstract}

\author{
AFFILIATION \\ 1 Department of Chest Diseases, Faculty of \\ Medicine, Assiut University, Assiut, Egypt

\section{CORRESPONDENCE TO} \\ Shereen Farghaly. Department of Chest \\ Diseases, Faculty of Medicine, Assiut \\ University, Assiut, 71515, Egypt. E-mail: \\ shereen@aun.edu.eg
}

\section{KEYWORDS}

nocturnal blood pressure, nocturnal blood pressure fluctuation index, OSAS, PSG

Received: 13 May 2021

Revised: 1 November 2021

Accepted: 21 November 2021

ABBREVIATIONS BPV: blood pressure variability, OSAS: obstructive sleep apnea syndrome, PSG: polysomnography, PTT: pulse transit time, AHI: apnea hypopnea index, REM: rapid eye movement, NREM: non rapid eye movement, ODI: oxygen desaturation index, T90: time spent below 90\%, NBPFI: nocturnal blood pressure fluctuation index, HTN: hypertension

\section{INTRODUCTION}

Nocturnal blood pressure (BP) has been reported to be a stronger predictor of cardiovascular morbidity and mortality than either daytime $\mathrm{BP}$ or clinic $\mathrm{BP}^{1,2}$. In addition to nocturnal $\mathrm{BP}$ level, nocturnal BP variability (BPV) has been found to be an independent predictor of cardiovascular events and mortality ${ }^{3}$. There is increasing evidence that fluctuations in BP levels are also associated with brain damage that may ultimately result in the development and progression of cognitive dysfunction ${ }^{4,5}$.

Obstructive sleep apnea syndrome (OSAS) induces repeated apneas and hypopneas, which causes repetitive intermittent hypoxia with consequent sympathetic activation leading to increased BP and heart rate, with repeated BP surges during sleep ${ }^{6,7}$. Thus, OSAS can lead to an increase not only in nocturnal BP level but also nocturnal BPV, each of which can independently increase cardiovascular risk ${ }^{8,9}$. Many studies have investigated hypertension $(\mathrm{HTN})^{10,11}$, nocturnal non dipping in OSAS patients ${ }^{12-14}$. However, no study has been conducted on OSAS patients without HTN to evaluate the influence of OSA on nocturnal BP fluctuations during sleep. The purpose of this study was to evaluate nocturnal blood pressure patterns and fluctuations in OSAS patients without hypertension and determine polysomnographic parameters associated with nocturnal blood pressure fluctuations.

\section{METHODS}

This is a retrospective cross-sectional study with 100 patients of OSA diagnosed as obstructive sleep apnea based on polysomnography (PSG) full-night attended sleep monitoring (apnea hypopnea index AHI >5) and not HTN or on anti-HTN medications.

\section{Exclusion criteria}

We excluded OSAS patients diagnosed by split-night PSG monitoring or sleep monitoring of duration $<3$ hours. OSAS patients combined with other sleep disorders as periodic leg 
movement syndrome or combined with advanced pulmonary or heart diseases were also excluded from the study.

\section{Data collection}

Data were collected from patients' medical records and polysomnographic reports. Demographic data including age, gender, BMI $\left(\mathrm{kg} / \mathrm{m}^{2}\right)$ were recorded.

\section{Awake BP data}

BP was measured using a mercury sphygmomanometer with stethoscope in the sitting position. The tourniquet was wrapped around the upper arm, keeping the arm at the same height of the heart, and a stethoscope was placed over the brachial artery. It was measured before bedtime during sleep monitoring (evening BP) and just after waking up (morning $\mathrm{BP}$ ), and an average was recorded for awake blood pressure. A patient with $\mathrm{BP} \geq 140$ systolic or $\geq 90$ diastolic was considered hypertensive ${ }^{14}$.

\section{Polysomnography}

Patients included in the study underwent full over-night attended diagnostic polysomnography (Somnomedics Somnoscreen plus device, Somnomedics, Randersacker, Germany). To record sleep stages, central and frontal EEG leads, electro-oculogram (EOG) and electromyogram of the chin (EMG) were applied. Pulse oximeter, oronasal flow thermistor and inductive plethysmography were applied for recoding oxygen variables, nasal and oral flow and thoracic and abdominal motion, respectively. Leg movements were recorded using surface electrodes placed around the middle of the tibialis anterior muscle. Other channels as ECG leads and a microphone were also applied.

\section{Nocturnal BP monitoring}

Continuous calibration of BP was started immediately after starting PSG device for all patients based on pulse transit time (PPT). PTT is defined as the time required for the arterial pulse pressure wave to travel from the aortic valve to periphery ${ }^{15}$. It can be estimated as the duration between the peak of the R wave in the ECG and the arrival of the corresponding pulse wave at the finger as determined by pulse oximetry. PTT is inversely related to BP. With increasing $\mathrm{BP}$, the arterial compliance decreases and pulse wave velocity increases and thus PTT shortens ${ }^{16}$.

The patient's BP was measured manually by a cuffbased method under resting conditions and upright sitting at start of PSG recording. The time point of this single BP measurement was entered manually at start of study. That cuff-based BP value was used for continuous calibration of the PTT based BP during the whole PSG recording using the DOMINO software.

\section{PSG scoring}

The test was scored automatically then sleep stages and respiratory events were manually revised by a sleep specialist. Those with $\mathrm{AHI} \geq 5$ with obstructive apneas were considered as cases of OSAS. Those with $\mathrm{AHI} \geq 30$ were considered severe cases of OSAS. Fifteen sleep parameters at Stage 1, Stage 2, Stage 3 and Stage REM were recorded. Parameters of respiratory events as AHI, T90 (min), ODI (oxygen desaturation index), average oxygen level, parameters of blood pressure during sleep (average systolic and diastolic BP, mean arterial pressure MAP, pulse pressure, nocturnal blood pressure fluctuation index NBPF) were recorded.

\section{PSG definitions}

- Obstructive apnea was defined as the absence of airflow for at least 10 seconds in the presence of respiratory effort.

- Hypopnea was considered when more than a 30\% drop in airflow occurred for more than 10 seconds, associated with at least 3\% oxygen desaturation or EEG arousal.

- $\mathrm{AHI}$ is the total number of apneas and hypopneas per hour of sleep.

- ODI is the number of episodes of oxygen desaturation per hour of sleep, where desaturation is defined as a drop in blood oxygen saturation to lower than 3\% below baseline that lasts for at least 10 seconds.

- T90 is the time spent in minutes during sleep when oxygen saturation is below $90 \%$.

- Average oxygen level is the mean oxygen saturation during sleep.

- NBPF index is the increase in systolic blood pressure by more than $12 \mathrm{mmHg}$ within 3-30 seconds of respiratory event per hour of sleep.

\section{Statistical analysis}

Statistical Package for the Social Sciences version 16 software (SPSS Inc.; Chicago, IL; USA) was used for analysis of results. Results are presented as mean \pm standard deviation or number and percentage. The qualitative data were compared between the groups using chi-squared test. The quantitative data were compared using Student's t-test. Spearman test was used for correlation analysis between NBPF index and respiratory sleep parameters. To predict factors associated with NBPF index, linear regression analysis was applied. A $p<0.05$ was considered significant.

\section{RESULTS}

The current study enrolled 100 patients with OSAS of whom $56 \%$ of patients were male. Their mean age was $56.3 \pm 11.7$ years. Their mean AHI was $51.5 \pm 27.4$. Their PSG parameters are presented in Table 1.

According to OSAS disease severity, patients were classified into non-severe OSAS $(n=56)$ and severe OSAS $(n=44)$ groups. BP parameters among the two groups are presented in Table 2. Average systolic and diastolic blood pressure during sleep were significantly higher in severe 
Table 1. Demographic data of the study population $(\mathrm{N}=100)$

\begin{tabular}{lc}
\hline Variable & Mean \pm SD \\
\hline Age (years) & $56.3 \pm 11.7$ \\
Gender, $n$ (\%) & \\
Male & $56(56)$ \\
Female & $44(44)$ \\
BMI (kg/m²) & $35.8 \pm 9.3$ \\
PSG sleep parameters & \\
\hline TST (h) & $3.4 \pm 0.4$ \\
\hline Stage 1 (min) & $24.9 \pm 10.9$ \\
Stage (min) & $42.8 \pm 19.01$ \\
Stage 3 (min) & $17.9 \pm 11.7$ \\
Stage REM (min) & $18.35 \pm 12.2$ \\
PSG respiratory parameters & \\
AHI (event/h) & $51.5 \pm 27.4$ \\
ODI (event/h) & $59.1 \pm 33.3$ \\
Average O2 saturation (\%) & $86.6 \pm 9.4$ \\
T9O (min) & $99.6 \pm 74.4$
\end{tabular}

PSG: polysomnography. BMI: body mass index. TST: total sleep time. REM: rapid eye

movement. AHI: apnea hypopnea index. ODI: oxygen desaturation index. T9O: time spent below $90 \%$.

Table 2. Comparison of awake and nocturnal BP parameters between non-severe OSA and severe OSA $(\mathrm{N}=100)$

\begin{tabular}{c|c|c|c} 
Variable & $\begin{array}{c}\text { Non-severe } \\
\text { OSA } \\
(n=56)\end{array}$ & $\begin{array}{c}\text { Severe } \\
\text { OSA } \\
(n=44)\end{array}$ & $p$ \\
& Mean \pm SD & Mean \pm SD &
\end{tabular}

\section{Awake BP}

\begin{tabular}{lrrc} 
Average systolic BP & $121.9 \pm 8.4$ & $122.3 \pm 7.6$ & 0.840 \\
\hline Average diastolic BP & $79.5 \pm 6.8$ & $79.8 \pm 4.5$ & 0.799 \\
\hline MAP & $93.6 \pm 6.7$ & $94.1 \pm 4.7$ & 0.790 \\
\hline Pulse pressure & $41.4 \pm 8.1$ & $41.2 \pm 6.5$ & 0.970 \\
\hline Sleep BP & & & \\
\hline Average systolic BP & $114.2 \pm 9.3$ & $120.1 \pm 7.2$ & $0.001^{*}$ \\
\hline Average diastolic BP & $73.8 \pm 9.9$ & $79.6 \pm 3.9$ & $<0.001^{*}$ \\
MAP & $87.3 \pm 8.9$ & $93.3 \pm 4.2$ & $0.005^{*}$ \\
\hline Pulse pressure & $41.4 \pm 8.1$ & $41.3 \pm 6.5$ & 0.931 \\
\hline NBPF index & $21.6 \pm 20.5$ & $41.4 \pm 21.9$ & $<0.001^{*}$ \\
NBPF max & $26 \pm 11.5$ & $26.5 \pm 13.8$ & 0.900 \\
\hline NBPF average & $18.5 \pm 8.6$ & $17.3 \pm 7.7$ & 0.632
\end{tabular}

BP: blood pressure. MAP: mean arterial pressure. NBPF: nocturnal blood pressure fluctuation. *Significant.

OSAS group compared to non-severe OSAS group (120.1 \pm 7.2 vs $114.2 \pm 9.3, p<0.001 ; 79.6 \pm 3.9$ vs $73.8 \pm 9.9$, $\mathrm{p}<0.001$, respectively). Of the nocturnal BP fluctuation
Table 3. Comparison of nocturnal BP parameters between REM and NREM stages $(\mathrm{N}=100)$

\begin{tabular}{l|c|c|c}
\hline Variable & $\begin{array}{c}\text { REM } \\
\text { Mean } \pm \text { SD }\end{array}$ & $\begin{array}{c}\text { NREM } \\
\text { Mean } \pm \text { SD }\end{array}$ & P \\
\hline Sleep BP & & & \\
Average systolic BP & $121.86 \pm 7.7$ & $119.8 \pm 7.8$ & $<0.001^{*}$ \\
\hline Average diastolic BP & $76.9 \pm 4.6$ & $74.9 \pm 4.7$ & $<0.001^{*}$ \\
\hline MAP & $91.8 \pm 4.9$ & $89.9 \pm 5.02$ & $<0.001^{*}$ \\
\hline Pulse pressure & $44.9 \pm 6.5$ & $44.1 \pm 6.6$ & 0.829 \\
NBPF index & $37.1 \pm 22.9$ & $36.7 \pm 22.6$ & $0.028^{*}$ \\
\hline NBPF max & $26.2 \pm 13.3$ & $25.1 \pm 11$ & 0.051 \\
\hline NBPF average & $17.6 \pm 7.9$ & $17.1 \pm 7.3$ & 0.027 * \\
\hline $\begin{array}{l}\text { BP: blood pressure. MAP: mean arterial pressure. NBPF: nocturnal blood pressure fluctuation. } \\
\text { *Significant. }\end{array}$ & & &
\end{tabular}

Figure 1. Correlation between NBPF index and AHI

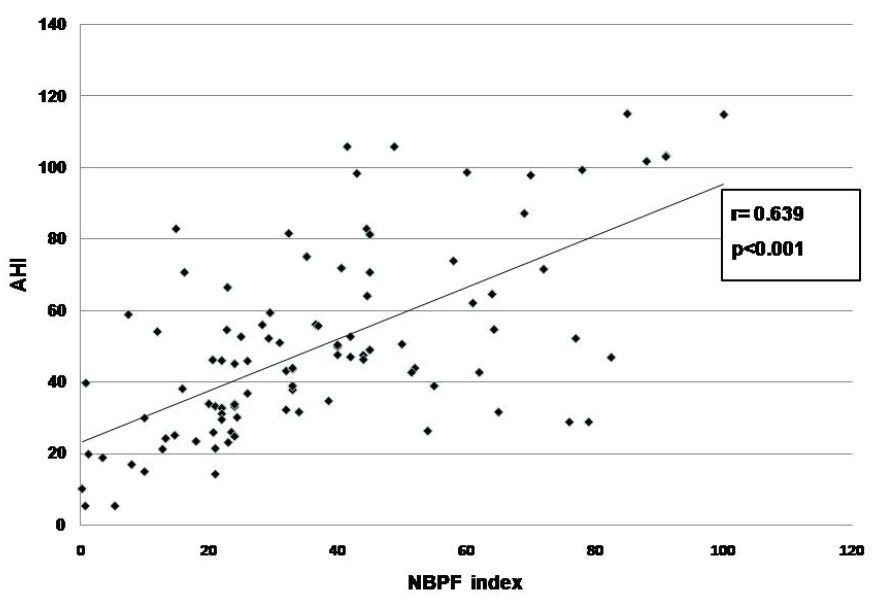

parameters, NBPF index was significantly higher in severe OSAS group compared to non-severe OSAS group (41.4 \pm 21.9 vs $21.6 \pm 20.5, p<0.001)$. However, no significant difference in all awake parameters were found between the two groups $(p<0.05)$.

Comparing BP parameters during sleep between rapid eye movement (REM) and non-rapid eye movement (NREM) sleep stages are presented in Table 3. Average systolic and average diastolic BP were significantly higher during REM stage compared to NREM (121.86 \pm 7.7 vs $119.8 \pm 7.8, p$ $<0.001 ; 76.9 \pm 4.6$ vs $74.9 \pm 4.7, p<0.001$, respectively). Of the nocturnal fluctuation parameters, NBPF index as well as average NBPF were significantly higher during REM stage compared to NREM stage (37.1 \pm 22.9 vs $36.7 \pm 22.6$, $\mathrm{p}=0.028 ; 17.6 \pm 7.9$ vs $17.1 \pm 7.3, \mathrm{p}=0.027$, respectively).

On univariate analysis, significant correlation was found between NBPF index and AHI $(r=0.639, p<0.001)$ (Figure 1), ODI ( $r=0.506, p<0.001$ ) (Figure 2$)$, average oxygen saturation $(r=-0.267, p=0.007)$ (Figure 3), and T90 ( $r=0.222, p=0.026)$ (Figure 4). By linear regression analysis, only $\mathrm{AHI}$ was a 
Figure 2. Correlation between NBPF index and ODI

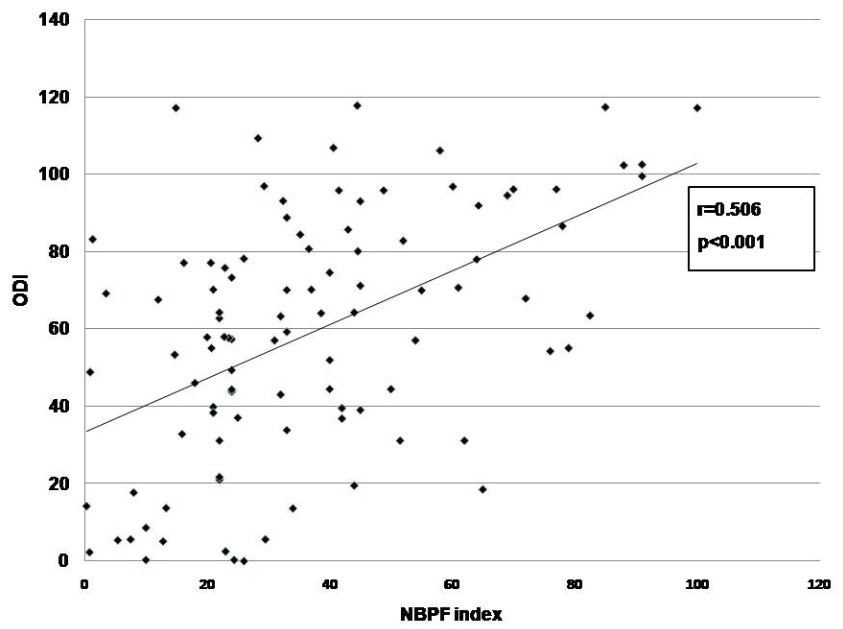

Figure 3. Correlation between NBPF index and average $\mathrm{O}_{2}$ saturation

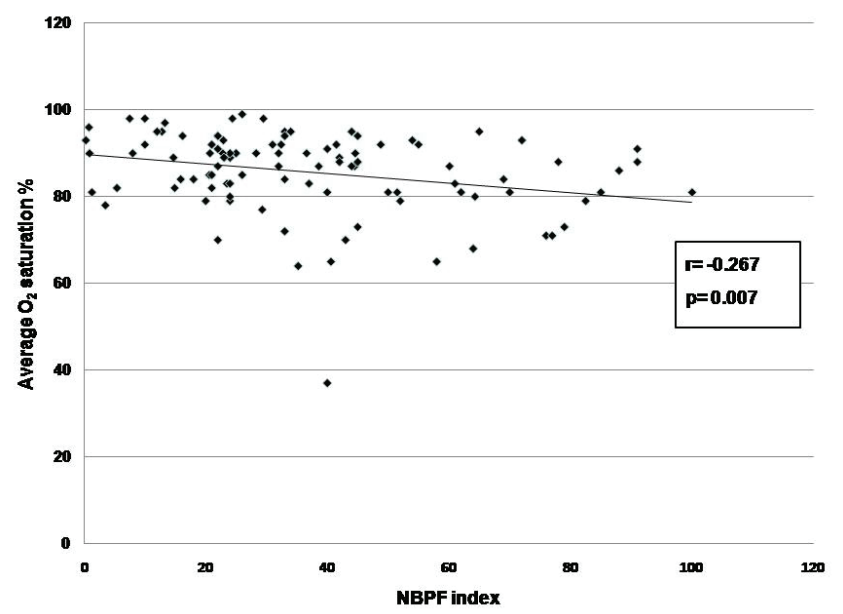

Figure 4. Correlation between NBPF index and T90 (min)

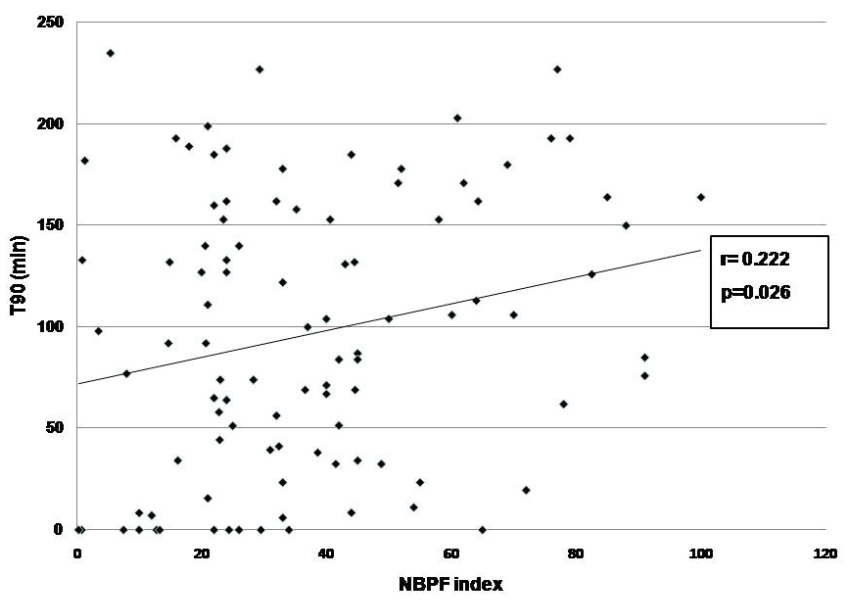

significant predictor associated with NBPF index $(p<0.001)$ (Table 4).
Table 4. Linear regression analysis to predict nocturnal blood pressure fluctuation index in OSA patients $(\mathrm{N}=100)$

\begin{tabular}{|c|c|c|c|}
\hline Variable & $\begin{array}{c}\beta \\
\text { coefficient }\end{array}$ & $\begin{array}{l}\text { Standard } \\
\text { error }\end{array}$ & $\mathbf{p}$ \\
\hline Age (years) & 0.156 & 0.158 & 0.055 \\
\hline BMI $\left(\mathrm{kg} / \mathrm{m}^{2}\right)$ & -0.037 & 0.094 & 0.631 \\
\hline AHI (event/h) & 0.724 & 0.107 & $<0.001^{*}$ \\
\hline $\begin{array}{l}\text { Desaturation } \\
\text { index }\end{array}$ & -0.101 & 0.100 & 0.466 \\
\hline $\begin{array}{l}\text { Average } \mathrm{O}_{2} \\
\text { saturation (\%) }\end{array}$ & -0.143 & 0.246 & 0.158 \\
\hline T90 (min) & 0.103 & 0.036 & 0.341 \\
\hline
\end{tabular}

BMI: body mass index. AHI: apnea hypopnea index. T90: time spent below 90\%. *Significant.

\section{DISCUSSION}

OSAS is considered a common cause of nocturnal sudden death ${ }^{17}$. Ohkubo et $a^{18}{ }^{18}$. related the mortality risk in OSAS patients to abnormal nocturnal blood pressure patterns. Many OSAS patients have non-dipping or rising BP pattern, and show BP surge in the early morning ${ }^{19}$. Nocturnal BP change is more useful to predict cardiovascular ${ }^{2}$ and cerebrovascular events ${ }^{4}$ than BP measured at clinic or home and awake BP. So the aim of this study was to evaluate nocturnal blood pressure patterns and fluctuations in OSAS patients without hypertension and determine polysomnographic parameters associated with nocturnal blood pressure fluctuations.

In this study, both average systolic and diastolic blood pressure during sleep were significantly higher in severe OSAS group compared to non-severe OSA group. NBPF index was also significantly higher in severe OSAS group compared to non-severe OSAS group as well. Previous studies have demonstrated increased arterial BP following obstructive apnea event in adult OSAS patients ${ }^{20-22}$. Furthermore, higher blood pressure levels and higher nocturnal blood pressure fluctuations were observed in severe OSAS compared to non-severe groups ${ }^{10,11}$. Several mechanisms have been proposed to explain the increase in BP during or after an obstructive respiratory event. The obstructive event during sleep is associated with increased negative intrathoracic pressure, hypoxia, hypercapnia, and arousal responses, and these changes induce increases in sympathetic activity ${ }^{23}$. During an obstructive event, the inhibitory effect of the thoracic afferents is absent, thus potentiating sympathetic activation ${ }^{24}$. As a result, vasoconstriction develops and causes a significant elevation in BP. At the end of the obstructive event, breathing resumes with abrupt elimination of vasoconstriction induced by apnea, allowing ejection of the augmented cardiac output into a peripheral vascular bed; thus, a transient increase in BP might occur in the immediate post-apnea period ${ }^{24,25}$. 
Comparing sleep BP parameters among sleep stages, that study reported significant elevation of systolic BP, diastolic blood pressure during REM stage compared to NREM stage. Nocturnal blood pressure fluctuation parameters were also more during REM compared to NREM stage. Nevertheless, controversies exist in the previous data regarding the effect of sleep stages on the BP changes during obstructive respiratory events. Jelic et al. ${ }^{26}$ found that systolic BP during both REM and NREM sleep showed reduction from awake state with an increase in the post-apnea period. Garpestad et al. ${ }^{20}$ also demonstrated a higher BP elevation during postobstructive events in both NREM and REM sleep, but the elevation was higher during REM sleep than during NREM sleep. In a population-based sample, mainly REM OSA is independently associated with non-dipping of BP in normotensive patients ${ }^{12}$.

REM induced marked hypotonia of upper airway genioglossus muscles can lead to longer apnea duration with more decrease in respiratory effort in response to upper airway occlusion during REM than NREM sleep ${ }^{27,28}$. Decrease in both hypoxic and hypercapnic ventilatory response during REM sleep compared to non-REM sleep were reported in previous studies ${ }^{29,30}$. Furthermore, apneic events were reported less frequent during slow wave sleep than REM ${ }^{31}$ and were usually associated with more hypoxemia in REM sleep $^{32}$.

From the factors associated with nocturnal BP fluctuation, this study found significant correlation between NBPF index and $\mathrm{AHI}$, ODI, average oxygen saturation and T90, with only $\mathrm{AHI}$ an independent predictor associated with NBPF index $(p<0.001)$. Each obstructive apnea event ends with a BP peak, which lasts for few seconds and then returns to baseline ${ }^{33}$. Therefore, the higher the number of apnea events, the more surges in BP. However, the amplitude of changes in BP could be related to degree of sympathetic activity, hypoxemia at end of apnea and normotensive/ hypertensive state ${ }^{34,35}$.

Controversies were reported in previous studies where some studies considered that hypoxia has the major effect on nocturnal blood pressure elevation ${ }^{30,36,37}$. Similarly, O'Donnell et al. ${ }^{38}$ in their animal study and Xu et al. ${ }^{39}$ suggest that mainly minimum oxygen saturation was associated with post-apneic BP elevation. Xu et al. ${ }^{40}$ also found that in severe OSAS, nocturnal BP levels were associated more with the nocturnal hypoxic duration and BP fluctuation than with $\mathrm{AHI}$. Crinon et al. ${ }^{14}$ detected an association between OSA severity and higher nocturnal BP in a normotensive cohort where intermittent hypoxia was the most important variable related to this BP fluctuation.

However, Ringler et al. ${ }^{41}$ failed to show suppression of apnea related BP elevation despite administration of oxygen. On the other hand, Davies et al. ${ }^{42}$ reported that auditory stimulation-induced arousal in normal subjects causes large elevation in nocturnal blood pressure, which could explain acute rise in BP seen in OSAS patients following apnea events. Yoon et al. ${ }^{43}$ also reported that apnea related arousal had the strongest correlation with BP elevation during sleep in OSAS patients. Wright et al. ${ }^{44}$, by regression analysis, revealed that average 24-h MAP and mean 24-h DBP were each best predicted by change in RDI.

\section{Limitations}

Lack of hypertensive group for comparison is the main limitation of the study. Due to small sample size in our study, we could not generalize results to the general population. Further studies are recommended to evaluate nocturnal blood fluctuation in OSAS patients and effect of treatment on their outcome.

\section{CONCLUSIONS}

Nocturnal blood pressure elevations and fluctuations are common in OSAS patients without HTN, which are more in severe OSAS patients than non-severe patients, and more during REM than NREM stages. AHI is the only dependent predictor associated with nocturnal blood pressure fluctuation in OSAS patients. Thus, it is suggested that OSAS patients are at cardiovascular and cerebrovascular risk and sudden cardiac arrest during sleep. Control of apnea by CPAP might decrease cardiovascular events in those patients.

\section{CONFLICTS OF INTEREST}

The authors have completed and submitted the ICMJE Form for Disclosure of Potential Conflicts of Interest and none was reported.

\section{FUNDING}

There was no source of funding for this research.

\section{ETHICAL APPROVAL AND INFORMED CONSENT}

The study was approved by the Faculty of Medicine Ethics Committee at Assiut University (No: 17300575, Dated: 9 March 2021). Informed consent was not required as data were collected from medical records.

\section{DATA AVAILABILITY}

The data supporting this research are available from the authors on reasonable request.

\section{PROVENANCE AND PEER REVIEW}

Not commissioned; externally peer reviewed.

\section{REFERENCES}

1. Boggia J, Li Y, Thijs L, et al. Prognostic accuracy of day versus night ambulatory blood pressure: a cohort study. Lancet. 2007;370(9594):1219-1229. doi:10.1016/S0140-6736(07)61538-4

2. Roush GC, Fagard RH, Salles GF, et al. Prognostic impact from clinic, daytime, and night-time systolic blood pressure in nine cohorts of 13844 patients with hypertension. J Hypertens. 2014;32(12):2332- 


\section{0. doi:10.1097/HJH.0000000000000355}

3. Somers VK, Mark AL, Zavala DC, Abboud FM. Influence of ventilation and hypocapnia on sympathetic nerve responses to hypoxia in normal humans. J Appl Physiol (1985). 1989;67(5):2095-2100. doi:10.1152/jappl.1989.67.5.2095

4. Tully PJ, Yano Y, Launer LJ, et al. Association Between Blood Pressure Variability and Cerebral Small-Vessel Disease: A Systematic Review and Meta-Analysis. J Am Heart Assoc. 2020;9(1):e013841. doi:10.1161/JAHA.119.013841

5. Lattanzi S, Vernieri F, Silvestrini M. Blood pressure variability and neurocognitive functioning. J Clin Hypertens (Greenwich). 2018;20(4):645-647. doi:10.1111/jch.13232

6. Somers VK, Mark AL, Zavala DC, Abboud FM. Contrasting effects of hypoxia and hypercapnia on ventilation and sympathetic activity in humans. J Appl Physiol (1985). 1989;67(5):2101-2106. doi:10.1152/jappl.1989.67.5.2101

7. Somers VK, Dyken ME, Mark AL, Abboud FM. Sympatheticnerve activity during sleep in normal subjects. N Engl J Med. 1993;328(5):303-307. doi:10.1056/NEJM199302043280502

8. Kario K. Obstructive sleep apnea syndrome and hypertension: ambulatory blood pressure. Hypertens Res. 2009;32(6):428432. doi:10.1038/hr.2009.56

9. Kario K. Obstructive sleep apnea syndrome and hypertension: mechanism of the linkage and 24-h blood pressure control. Hypertens Res. 2009;32(7):537-541. doi:10.1038/hr.2009.73

10. Williams B, Mancia G, Spiering W, et al. 2018 ESC/ESH Guidelines for the management of arterial hypertension: The Task Force for the management of arterial hypertension of the European Society of Cardiology (ESC) and the European Society of Hypertension (ESH). Eur Heart J. 2018;39(33):3021-3104. doi:10.1093/eurheartj/ehy339

11. Steinhorst AP, Gonçalves SC, Oliveira AT, et al. Influence of sleep apnea severity on blood pressure variability of patients with hypertension. Sleep Breath. 2014;18(2):397-401. doi:10.1007/s11325-013-0899-z

12. Martynowicz H, Porębska I, Poręba R, Mazur G, Brzecka A. Nocturnal Blood Pressure Variability in Patients with Obstructive Sleep Apnea Syndrome. Adv Exp Med Biol. 2016;952:9-15. doi:10.1007/5584_2016_64

13. Mokhlesi B, Hagen EW, Finn LA, Hla KM, Carter JR, Peppard PE. Obstructive sleep apnoea during REM sleep and incident non-dipping of nocturnal blood pressure: a longitudinal analysis of the Wisconsin Sleep Cohort. Thorax 2015;70(11):1062-1069. doi:10.1136/thoraxjnl-2015-207231

14. Crinion SJ, Kleinerova J, Kent B, et al. Non-dipping nocturnal blood pressure correlates with obstructive sleep apnoea severity in normotensive subjects and may reverse with therapy. ERJ Open Res. 2021;7(3):00338-2021. doi:10.1183/23120541.00338-2021

15. Smith RP, Argod J, Perin JL, Levy PA. Pulse transit time: an appraisal of potential clinical applications. Thorax. 1999;54(5):452-457. doi:10.1136/thx.54.5.452

16. Berry RB, Budhiraja R, Gottlieb DJ, et al. Rules for Scoring Respiratory Events in Sleep: Update of the 2007 AASM
Manual for the Scoring of Sleep and Associated Events. Deliberations of the Sleep Apnea Definitions Task Force of the American Academy of Sleep Medicine. J Clin Sleep Med. 2012;8(5):597-619. doi:10.5664/jcsm.2172

17. Gami AS, Howard DE, Olson EJ, Somers VK. DayNight Pattern of Sudden Death in Obstructive Sleep Apnea. N Engl J Med. 2005;352(12):1206-1214. doi:10.1056/NEJMoaO41832

18. Ohkubo T, Imai Y, Tsuji I, et al. Relation Between Nocturnal Decline in Blood Pressure and Mortality: The Ohasama Study. Am J Hypertens. 1997;10(11):1201-1207. doi:10.1016/s0895-7061(97)00274-4

19. Kario K. Time for Focus on Morning Hypertension: Pitfall of Current Antihypertensive Medication. Am J Hypertens. 2005;18(2):149-151. doi:10.1016/j.amjhyper.2004.09.007

20. Garpestad E, Ringler J, Parker JA, Remsburg S, Weiss JW. Sleep stage influences the hemodynamic response to obstructive apneas. Am J Respir Crit Care Med. 1995;152(1):199-203. doi:10.1164/ajrccm.152.1.7599824

21. Garpestad E, Katayama H, Parker JA, et al. Stroke volume and cardiac output decrease at termination of obstructive apneas. J Appl Physiol (1985). 1992;73(5):1743-1748. doi:10.1152/jappl.1992.73.5.1743

22. Ali NJ, Davies RJO, Fleetham JA, Stradling JR. The Acute Effects of Continuous Positive Airway Pressure and Oxygen Administration on Blood Pressure during Obstructive Sleep Apnea. Chest. 1992;101(6):1526-1532. doi:10.1378/chest.101.6.1526

23. Séi $H$. Blood pressure surges in REM sleep: A mini review. Pathophysiology. 2012;19(4):233-241. doi:10.1016/j.pathophys.2012.04.006

24. Dempsey JA, Veasey SC, Morgan BJ, O'Donnell CP. Pathophysiology of Sleep Apnea. Physiol Rev. 2010;90(1):47112. doi:10.1152/physrev.00043.2008

25. Lanfranchi PA, Pépin JL, Somers VK. Cardiovascular Physiology: Autonomic Control in Health and in Sleep Disorders. In: Kryger MH,Roth T, Dement WC, eds. Principles and Practice of Sleep Medicine. 6th ed. Elsevier; 2017:142154. doi:10.1016/C2012-0-03543-0

26. Jelic S, Bartels MN, Mateika JH, Ngai P, DeMeersman RE, Basner RC. Arterial Stiffness Increases During Obstructive Sleep Apneas. Sleep. 2002;25(8):15-20. doi:10.1093/sleep/25.8.15

27. Krieger J, Sforza E, Boudewijns A, Zamagni M, Petiau C. Respiratory Effort During Obstructive Sleep Apnea: Role of Age and Sleep State. Chest. 1997;112(4):875-884. doi:10.1378/chest.112.4.875

28. McSharry DG, Saboisky JP, Deyoung P, et al. Physiological Mechanisms of Upper Airway Hypotonia during REM Sleep. Sleep. 2014;37(3):561-569. doi:10.5665/sleep.3498

29. Douglas NJ, White DP, Weil JV, Pickett CK, Martin RJ, Hudgel DW, Zwillich CW. Hypoxic Ventilatory Response Decreases During Sleep in Normal Men. Am Rev Respir Dis 1982;125(3):286-289. doi:10.1164/arrd.1982.125.3.286 30. Douglas NJ, White DP, Weil JV, Pickett CK, Zwillich 
CW. Hypercapnic Ventilatory Response in Sleeping Adults. Am Rev Respir Dis. 1982;126(5):758-762. doi:10.1164/arrd.1982.126.5.758

31. Ratnavadivel R, Chau N, Stadler D, Yeo A, McEvoy RD, Catcheside PG. Marked Reduction in Obstructive Sleep Apnea Severity in Slow Wave Sleep. J Clin Sleep Med. 2009;5(6):519-524. doi:10.5664/jcsm.27651

32. Findley LJ, Wilhoit SC, Suratt PM. Apnea Duration and Hypoxemia During REM Sleep in Patients with Obstructive Sleep Apnea. Chest. 1985;87(4):432-436. doi:10.1378/chest.87.4.432

33. Tun Y, Okabe S, Hida W, et al. Nocturnal blood pressure during apnoeic and ventilatory periods in patients with obstructive sleep apnoea. Eur Respir J. 1999;14(6):1271-1277. doi:10.1183/09031936.99.14612719

34. Lofaso F, Goldenberg F, d'Ortho MP, Coste A, Harf A. Arterial Blood Pressure Response to Transient Arousals From NREM Sleep in Nonapneic Snorers With Sleep Fragmentation. Chest. 1998;113(4):985-991. doi:10.1378/chest.113.4.985

35. Planès C, Leroy M, Fayet G, Aegerter P, Foucher A, Raffestin B. Exacerbation of sleep-apnoea related nocturnal bloodpressure fluctuations in hypertensive subjects. Eur Respir J. 2002;20(1):151-157. doi:10.1183/09031936.02.00272202

36. Narkiewicz K, van de Borne PJH, Pesek CA, Dyken ME, Montano N, Somers VK. Selective Potentiation of Peripheral Chemoreflex Sensitivity in Obstructive Sleep Apnea. Circulation. 1999;99(9):1183-1189. doi:10.1161/01.cir.99.9.1183

37. Leuenberger U, Jacob E, Sweer L, Waravdekar N, Zwillich C, Sinoway L. Surges of muscle sympathetic nerve activity during obstructive apnea are linked to hypoxemia. J Appl Physiol (1985). 1995;79(2):581-588. doi:10.1152/jappl.1995.79.2.581

38. O'Donnell CP, Ayuse T, King ED, Schwartz AR, Smith PL, Robotham JL. Airway obstruction during sleep increases blood pressure without arousal. J Appl Physiol (1985). 1996;80(3):773-781. doi:10.1152/jappl.1996.80.3.773

39. Xu J, Ding N, Chen L, et al. Inducers of post-apneic blood pressure fluctuation monitored by pulse transfer time measurement in obstructive sleep apnea varied with syndrome severity. Sleep Breath. 2019;23(3):769-776. doi:10.1007/s11325-018-1770-z

40. Xu J, Ding N, Zhang X, et al. Nocturnal blood pressure fluctuation and associated influential factors in severe obstructive sleep apnea patients with hypertension. Sleep Breath. 2018;22(4):1045-1052. doi:10.1007/s11325-018-1634-6

41. Ringler J, Basner RC, Shannon R, et al. Hypoxemia alone does not explain blood pressure elevations after obstructive apneas. J Appl Physiol (1985). 1990;69(6):2143-2148. doi:10.1152/jappl.1990.69.6.2143

42. Davies RJ, Belt PJ, Roberts SJ, Ali NJ, Stradling JR. Arterial blood pressure responses to graded transient arousal from sleep in normal humans. J Appl Physiol (1985). 1993;74(3):1123-1130. doi:10.1152/jappl.1993.74.3.1123

43. Yoon IY, Jeong DU. Degree of Arousal Is Most Correlated with Blood Pressure Reactivity During Sleep in Obstructive Sleep Apnea. J Korean Med Sci. 2001;16(6):707-711. doi:10.3346/jkms.2001.16.6.707

44. Wright JT Jr, Redline S, Taylor AL, et al. Relationship Between 24-H Blood Pressure and Sleep Disordered Breathing in a Normotensive Community Sample. Am J Hypertens. 2001;14(8):743-748. doi:10.1016/s0895-7061(01)01299-7 